\title{
Reading for Independence
}

Carol A. Fraser

\begin{tabular}{|c|c|}
\hline $\begin{array}{l}\text { Reading authentic texts, especially those } \\
\text { associated with their subject-matter } \\
\text { courses, poses continuing difficulty for } \\
\text { ESL university students. One way to help } \\
\text { these students develop efficient, indepen- } \\
\text { dent reading skills is to develop their } \\
\text { strategic competence. This article outlines } \\
\text { a direct teaching approach which aims to } \\
\text { teach students to efficiently and effectively } \\
\text { apply their knowledge of the English lan- } \\
\text { guage and of good reading behaviour to }\end{array}$ & $\begin{array}{l}\text { the second language reading task. In this } \\
\text { approach, students are introduced to proce- } \\
\text { dures that require them to apply language } \\
\text { and skill knowledge to solve such second } \\
\text { language reading problems as unfamiliar } \\
\text { words or an inflexible reading style. } \\
\text { Through the experience of using these pro- } \\
\text { cedures, it is hypothesized that students } \\
\text { will develop their own routines for making } \\
\text { effective use of the knowledge sources } \\
\text { available. }\end{array}$ \\
\hline
\end{tabular}

Reading authentic texts, especially those associated with their subjectmatter courses, poses continuing problems for ESL university students in spite of the fact that they are at advanced proficiency levels and have usually successfully completed advanced level ESL programmes. Common student complaints include:

- too many unknown words

- long and complex sentences

- too much to read within time limits

- difficulty applying what is read to outside tasks.

The source of this difficulty is in itself complex. Students may lack the needed language knowledge, reading skill and/or the prerequisite conceptual/cultural knowledge. There may be a poor transfer of $\mathrm{L} 1$ reading skill due either to weak L2 skills or a difficult text which causes them to regress to a word-by-word reading strategy (Dubin, Eskey, and Grabe 1986). As well, students may have difficulty in being able to demonstrate their comprehension. They may read and comprehend but might not internalize the information in a language or organizational framework so that they are: able to communicate it (Manzo and Eanet 1976).

How to best help our advanced ESL students bridge the gap from teacher- or text-sequenced, and directed reading activities to the efficient independent processing of text remains the challenge for the ESL teacher in the university.

One current and widely used methodological response has been to simulate the university subject-matter reading task by means of the content- 
focussed, ESL class (Mohan 1985). In the content class, the student gains experience doing real tasks with authentic materials in a supportive environment where input and feedback can be adjusted to ESL needs. In other words, the teacher guides and directs the students through a series of simulated reading tasks. It is assumed that the student will gradually acquire the necessary language and cognitive skills through actual use and appropriate feedback on that use. While students exposed to such an approach gain valuable experience in using their second language for a variety of purposes and thus gain in their overall language competence, this approach tends to neglect an important aspect in the development of skilled reading behaviour-namely the development of strategies. A strategy here refers to an individual's way of approaching a given reading task. Skilful reading involves not only having the necessary knowledge (language, world, reading process) but also having the necessary strategic competence or the knowledge of how to apply this knowledge effectively and efficiently (Van Dijk and Kintsch 1982). Developing students' strategic competence or know-how when confronted with a second language reading task is the focus of an instructional approach $I$ have been experimenting with in the last few years. The goal of this approach is to teach intermediate and advanced English for Academic Purposes (EAP) students strategies that they are able to apply independently while reading in their second language. By focussing on developing strategic competence for reading, this approach can complement the language knowledge and skills developed through experiential content-focussed language teaching approaches.

\section{Framework for Strategy Development}

In ESL instruction (classroom and textbook activities), reading strategies such as skimming, scanning, previewing, or predicting word meaning from context are typically presented and practised by the student as exercises separated from and carried out either before or after the actual reading. By going through the prescribed exercises, students are expected to infer how their knowledge about these strategies can be effectively applied to other second language reading tasks. In my experience, students haven't necessarily transferred this knowledge about useful reading strategies to a knowledge of how to use these strategies effectively for a specific second language reading task. Perhaps students don't see how these strategies apply to the more complex reading task, or perhaps the context of the task itself is so different that the processing requirements are different. Because of this apparent lack of transfer of specific reading strategies that are practised in isolation to the ability to effectively apply these strategies while reading on their own, it seemed useful from an instructional viewpoint to focus on helping the student develop effective 
strategies that they could apply while actually reading to either solve comprehension breakdowns or to efficiently process a text to accomplish a specific task. But what is an effective approach to developing student strategic competence?

Although we currently do not fully understand how a student develops strategic competence or what instructional practices affect that development, there has been some experimental classroom research in cognitive science that has focussed on the development of strategic competence in native language students. Even though this research focusses on the development of strategies in native language students, it is relevant to the development of strategies in the second language student because strategies relate to underlying cognitive processes (the way information is accessed and processed via language and thinking skills) and thus are not language specific. Both cognitive theory (Van Dijk and Kintsch, 1982) and second language acquisition theory (Stern, 1983; Bialystok, 1978) support the notion that the underlying cognitive processes of language learning, whether in a first or a second language context, are the same. Moreover, Block (1986) in comparing the comprehension strategies of L1 and L2 university students found that there were no differences in patterns of strategy use between the two groups and concluded: "Thus, the development of strategy use, particularly as it is applied to informative text, does not seem to depend on language specific features" (p. 485).

In general, this research on the development of strategic behaviour suggests that strategies, especially those dealing with higher order cognitive processes such as those involved in reading comprehension or written composition, are more effectively taught using a direct teaching approach rather than an indirect one. Direct teaching refers to the explicit explanation, demonstration, and practice of selected strategies, while indirect teaching refers to the teacher modelling of the strategy or the students going through a prescribed set of practice exercises without any explicit instruction about the strategy in terms of when and how to apply it.

Bird (1980) looked at whether reading strategies in their initial stage of acquisition were better taught directly or indirectly. She hypothesized that a direct teaching approach would be more effective than an indirect one because a key factor in the initial stage of strategy acquisition is student awareness, in the sense of both paying attention and understanding what is to be attended to. In addition, a direct approach with its explicit explanation, demonstration, and practice, better ensures student awareness than an indirect one which lacks explicit instruction, and therefore leaves it up to the student to spontaneously develop the appropriate strategies and to infer information regarding their appropriate use. In her research, Bird directly taught native language students reading strategies such as paraphrasing to help clarify confusing or complex sentences or backtracking 
to an appropriate spot when there is a comprehension breakdown. The effects on the use of strategies and on reading comprehension of this direct teaching approach were compared to a modelling approach, an oral and written exercise approach, and a no-teaching approach. The direct teaching approach was more effective in improving both students' use of strategies and overall reading comprehension. Bird's research suggests not only that reading strategies can be taught directly but that this direct teaching of reading strategies positively affects reading comprehension.

In another experimental study, Scardamalia (1984) examined whether the direct teaching of strategies has a positive affect on student composing abilities. Scardamalia developed a direct teaching approach (procedural facilitation) to develop in students an awareness of what good composing strategies, specifically in the areas of content generation and planning, are. Students were first sensitized to expert composing behaviour. Then, students were given aids (cue cards) to help them incorporate this expert behaviour into their own composing processes. For example, cue cards that focussed on planning strategies for factual exposition included such prompts as A goal I think I could write to . . or If I want to start off my strongest idea, I'll ... (p. 28). By using external aids, students were gradually trained to an increasing independent and appropriate use of specific strategies. This research shows that the procedural model of direct teaching can positively affect students' independent composing abilities. It also suggests that the direct teaching of strategies is more effective than an indirect method because in the indirect mode it is the teacher or text who does the thinking or processing not the student, while in the direct mode students themselves do the processing and gradually develop their own strategies for complex processing tasks.

Research thus suggests that one useful instructional way to influence the development of student strategic competence, particularly in higher order cognitive processes such as reading comprehension or written composition, is to use a direct teaching approach. Moreover, what seems to be important in the direct teaching model is, first, that students be made aware both of what the strategy is and how it is applied and, secondly, that the students themselves engage actively in the processing problem in the sense that they do the thinking and applying of strategies even if in the initial stage of learning they are given external support such as the procedure to follow.

\section{A Direct Teaching Approach to Develop ESL Reading Strategies}

Within this framework for strategy development, a direct teaching approach has been developed at York University that aims to develop in ESL students strategies to effectively apply their knowledge of the English 
language and of the reading process to the second language reading task. This approach has been used with university level EAP students of advanced ESL proficiency in two settings at York University: with a multicultural group of students in a workshop setting for the Counselling and Development Centre, and with francophone students in a one-semester course entitled Non-literary Texts.

In this direct teaching approach, students are presented various procedures which they are asked to use to solve specified reading problems, problems noted either by students or the instructor. These procedures consist of a systematized sequence of steps that require the student to apply language knowledge and reading process knowledge to solve a reading problem. The procedures are designed to be applied by the students on their own while actually reading. Through the experience of using these procedures, students gain experience applying language and reading skill knowledge strategically while they read. This should facilitate the development of strategic competence in the sense of their developing effective ways of approaching second language reading tasks by making efficient use of the knowledge sources available.

To date, two types of procedures have been developed: Coping Procedures that help the student cope with a comprehension breakdown (Word Analysis Procedure, Sentence Analysis Procedure), and Smart ESL Reading Procedures which aim to direct the student to efficiently attack a second language reading task (Determining a Purpose, Determining Relations Between Ideas).

The overall methodology of the approach is that an issue is presented and discussed in class, any prerequisite language or skill knowledge is introduced, and on the basis of this language and skill knowledge, a procedure responding to the problem is either presented to or developed with students. Finally, the procedure is explained, demonstrated, and practised. As the term progresses, the repertoire of strategies increases and part of the goal becomes to encourage students to be selective in their choice of strategy to apply.

\section{Unit Example}

As an illustration, a typical way of proceeding with a unit that focusses on developing vocabulary strategies will be described. An outline of the other units and procedures is included in the appendix.

A lack of vocabulary and an inability to deal with unknown words is a perennial complaint of second language readers. In discussing the issue with students, it appears that the problem is both how to cope with unknown words while reading and how to increase their vocabulary through reading. Both these issues are examined with students in the light 
of what is known about reading and vocabulary acquisition and the place of vocabulary in reading comprehension. Issues usually dealt with include:

- how new vocabulary is learned

- whether it is necessary to know every word to comprehend a text

- what happens to a reader's understanding of a text if they stop in mid-sentence to go to the dictionary

- what students do when they come across an unknown word in their native language.

Next, students are introduced to information about words in English: how they are structured and how they operate in a text. Students are introduced to how words are built in English; how adding a prefix to a root can lead to a change in meaning (e.g. un + happy $\rightarrow$ unhappy) and how adding a suffix to a root can lead to a change in grammatical function (e.g. happy + ness $\rightarrow$ happiness). Students are also presented the most common prefixes and suffixes. In practice exercises, students may be cued to look for meaningful roots in an unfamiliar word or to determine a word's grammatical function according to suffixes. The teaching goal here is not for students to learn the rules of word formation or memorize the common prefixes and suffixes but rather to become familiar with one resource for deciphering unknown vocabulary. An analysis of the structure of an unknown word may help the student figure out its meaning or even determine that because of the word's grammatical function, it is not necessary to decode it for text comprehension. For example, an adjective may not be as important to overall text interpretation as a noun.

As well, lexical cohesion or how words are used to help tie a text together is examined. One lexical tie writers typically use is, instead of repeating the same word throughout a text, to use synonyms such as kids or offspring as synonyms for children. Or, a writer might use a superordinate word as a synonymous substitute. For example, animal is used as a superordinate substitute for $d o g$ in: The $d o g$ barked. The animal must have heard a noise. As a practice exercise, students can be cued to look for all the different words a writer uses to express a key concept in a given text. The teaching goal is for students to become aware that a writer will often express a key concept using a variety of words and that, consequently, an unfamiliar word may have a recognizable synonym close-by.

Finally, students are introduced to the Word Analysis Procedure (figure 1). The rationale for the different steps is considered, and students practise applying it. This is followed by a discussion of problems that arose. 


\section{Figure 1. Word Analysis Procedure}

Sometimes in reading academic texts, you come across words that you don't recognize. This Word Analysis Procedure aims to help you figure out what the word may mean without going to the dictionary.

1. Underline the unknown word. Continue reading at least to the end of the paragraph. If that word is important to be able to continue go to 2 .

2. Reread the sentence leaving the unknown word out. Try to substitute another word (in English or your native language) that makes sense according to the context. If successful, continue reading; if not, go to 3 .

3. Analyse the word in its semantic and/or structural context:

Is it a synonym for another word in this text?

Can you break the word down into roots you know?

What is its grammatical function?

(noun, adjective, adverb, verb)

Now Can You Find A Substitute?

The purpose of the Word Analysis Procedure (WAP) is to guide students to apply smart reading behaviour knowledge and language knowledge to a second language reading problem in order to cope with unfamiliar words. Because individual word meaning is modified by its use in a specific context, students are taught that it is better to look to the text itself for word meaning than to go to a dictionary. Students are also taught that the structure of the word may be used to decipher an unfamiliar word or to determine whether that word is important for overall text interpretation.

Student response to the WAP has been consistently positive. First of all, students are given something concrete and systematic to do when faced with unfamiliar vocabulary. This eases anxiety and allows them to continue to read for meaning rather than go to the dictionary and thus short-circuit the reading process. Although some students initially balk at the notion of not looking up unknown words in a dictionary, a few examples of how unhelpful and sometimes misleading a dictionary can be in giving information about word meaning in a specific context, and how often a close look at the sentence containing the unknown word (Step 2 in the WAP) allows them to come up with an acceptable interpretation, quickly changes this skeptical attitude. Through using the WAP, students gain confidence and skill in dealing with unknown words. They learn that they don't have to know the meaning of every word to understand a text, that often a sense of the gist of a word from its surrounding context is sufficient for text interpretation, and that a close look at the surrounding lexical context and/or word structure often helps to understand individual word meaning. Students report that they like WAP because it saves them 
time in their reading and they have little difficulty in applying it. Some have even reported that this attention to how words work and relate in text has helped increase their vocabulary through reading.

\section{Conclusion}

This article has reported on a direct teaching approach that is currently used at York University to develop independent reading strategies in advanced level university students. This approach was developed in response to an observed need for advanced proficiency ESL students to develop effective ways of approaching second language reading tasks that they could apply on their own. A direct teaching approach was adopted because of indications from research (Bird, 1980; Scardamalia, 1984) that strategic competence can be effectively developed using an instructional approach in which students are explicitly made aware of both what the strategy is and how it can be applied in specific contexts.

In this direct teaching approach, the instructor focusses student attention on problems associated with the second language reading task. Students are then introduced to specific procedures to follow when faced with a particular reading problem. The aim of these procedures is to direct the student to apply language and reading knowledge strategically while they are reading. Through demonstration, practice, and discussion, students are encouraged to apply the procedure to actual reading tasks. Through the experience of applying this knowledge systematically, it is hypothesized that students develop strategic competence in that they internalize effective ways of using knowledge about language and knowledge about reading in a second language.

It must be emphasized that this approach was developed as a methodological response to an observed instructional problem. To date, it has been used in limited contexts (a few instructors, intermediate-advanced proficiency level EAP students, a university setting) and feedback regarding the effectiveness of the approach is based on instructor and student observations. As well, the relation between the focus of this approach on explicit strategy development and the subsequent development of strategic competence is tentative. Considering the importance attached to the acquisition of good reading strategies in current views of the reading process (Van Dijk and Kintsch, 1982), it appears that there is a need for more research to investigate the role of strategies in the second language reading process, the mechanisms of strategy development, and the instructional practices which affect that development.

From a teaching perspective, this approach to developing strategies in response to specific second language reading problems has certain advan- 
tages because of the flexibility inherent in the procedures. First, since the procedures specifically focus on one aspect of reading skill, the development of strategic competence, they do not represent a total reading method or programme but rather are an instructional tool that the instructor can select, sequence, and use as need arises. Although all groups at York have used the Word Analysis Procedure, many groups did not use the Sentence Analysis Procedure as it was not relevant to their needs. Moreover, because these procedures are not tied to any specific methodology, they can be effectively integrated into a variety of programmes. At York, they have been used as an adjunct to a theme-based EAP course, as part of a course focussing on reading, and in a workshop setting. As well, they can be used with any text and adapted for a variety of reading tasks. For example, in one group the circling of key logical connectors proved to be a useful strategy for students to determine the bias of newspaper articles. The logical connectors of concession (e.g. but, although) were one of the frequent linguistic ways that writers signalled their bias.

Student response to this focus of instruction on the development of effective reading strategies has been encouraging. Students readily apply themselves to trying out the strategies in a variety of second language reading contexts. Class discussions, especially those that focus on comparing reading behaviour in first and second languages and on how well a specific procedure works is lively. Students have astute perceptions regarding what works and what doesn't and often a clear idea of why. For example, one group in discussing the difference between previewing and skimming as strategies for getting the general idea of what a text is about (Reading Flexibly Unit) observed that in second language reading tasks, previewing worked better than skimming. In class discussion, it became apparent that the majority found skimming much harder to do than previewing. In previewing, the reader reads complete sentences while in skimming, the reader has to pick out key words as their eyes race across the page. To skim well, the reader must be able to precisely predict where the key words are, quickly identify them in terms of their meaning and grammatical function and then construct meaning on the basis of this partial syntactic information. Effective skimming, thus, requires a highlevel grammatical-expectancy competence, an ability even advanced ESL students may lack, particularly, when it comes to complex academic texts. This class discussion led students to re-evaluate their potential use of the skimming strategy when reading in the second language and led the instructor to consider the possibility that such general reading strategies as skimming, scanning, previewing may have different (wider or more limited) applications in second language reading than in first language reading. 


\section{Appendix}

\section{Sample Unit: Sentence Comprehension}

I. Issue Presentation and Discussion

Students often have trouble comprehending long, complex sentences.

II. Development of Prerequisite Background Knowledge

a) Skill knowledge:

- Identifying main subjects and main verbs helps students comprehend long, complex sentences (Pierce 1972). In English written text, the majority of time the main verb follows the subject directly.

This information can be used to help decipher a difficult sentence.

- Individual authors often write with a repetitive sentence structure style. Analysing a new author's sentence style can help you read more efficiently.

b) Language knowledge:

- base sentences patterns

- coordinate sentence patterns (and/but/yet/or/for/so)

- subordinate sentence patterns (adjective, noun, adverb clauses)

- the difference in function between coordinate and subordinate clauses.

III. Procedure Presentation:

(explanation, demonstration, practice, discussion)

\section{Sentence Analysis Procedure}

Sometimes in reading academic texts, you come across very long and complex sentences that you find difficult to understand. This Sentence Analysis Procedure aims to help you break the sentence down into meaningful components for better comprehension.

1. Circle all words or punctuation marks that signal co-ordinate or subordinate clause relationships.

2. Underline the subjects and verbs of all main clauses.

E.g. Although the wind was blowing fiercely the fishermen decided to head out for the banks@indry their luck for a good haul.

3. Analyse the relationships between clauses.

What is the main action? What happens?

What function do subordinate clauses play?

- modify?

- qualify?

- express time, cause, purpose, condition etc.

4. Paraphrase the main point of the sentence.

\section{Sample Unit: Determining Relations}

I. Issue Presentation and Discussion

Students may have trouble comprehending the relations between ideas (main idea to a supporting point to an example of). Or, although students may 
comprehend, they have trouble demonstrating their comprehension. They have trouble remembering or expressing their understanding. They don't seem to have internalized meaning within a language or organizational framework that can be easily accessed.

II. Development of Prerequisite Background Knowledge

a) Skill knowledge:

- previewing

- identifying information blocks (Blanton, 1984) and labelling them in terms of discourse function.

b) Language knowledge:

- language signals that link ideas:

- coordinate + subordinate conjunctions

- text cohesion (pronouns, proverbs, certain adjectives)

- discourse markers-sequence (first, next)

-illustrative (for example)

-contrastive (nevertheless)

III. Procedure Presentation:

(explanation, demonstration, practice, discussion)

\section{Determining Relations Between Ideas}

Sometimes when you read an academic text, you have the feeling that even though you understand the individual words and sentences, you don't understand the whole or can't remember what you read. This procedure aims to help you by focussing on the relationships between ideas.

1. Preview the text in order to determine the subject, the author's specific focus and the major blocks of information.

2. As you re-read, separate the major blocks of information with a line and label them in the margin.

3. Circle any language that signals important relations between ideas-discourse markers (nevertheless, for example, in fact); conjunctions (because, although, but, so); structural ties (the former, the latter, one another, "this" attitude).

4. Use your labels and circled markers to guide you to recite or write a brief summary of the main and supporting ideas.

\section{Sample Unit: Reading Flexibly}

I. Issue Presentation and Discussion

Students tend to read all texts in the same way and may regress to a word-byword reading strategy especially with difficult texts.

Students seem to have problem defining or specifying their purpose in reading a given text and in applying flexible reading strategies according to that purpose. 
II. Development of Prerequisite Background Knowledge

a) Skill knowledge:

- range of purposes in reading-Read " $\mathrm{x}$ " can mean many things from learn this for tomorrow to rock yourself to sleep.

- range of possible strategies:

- Previewing: to get general idea of heavy reading.

- Skimming: to review or to get general idea of light reading.

- Scanning: to identify specific information

- Labelling and/or highlighting: to note for study purposes.

- Creating Questions: such as SQ3R technique for study purposes.

- Different purposes require different reading strategies. Discuss flexible reading strategies to accomplish task. Would you read the whole text? quickly? slowly? make notes? underline certain words?

III. Procedure Presentation:

(explanation, demonstration, practice, discussion)

\section{Determining a Purpose}

Why you read a text determines how you read it. Reading speed, the kind of information you select to focus on, and how you remember the information depends on your purpose in reading. The clearer your purpose, the more efficient your reading.

1. Has the purpose for reading this text been specified?

Possible purposes: $\bullet$ to pick out main ideas.

- to answer a specified question.

- to evaluate the information.

If the purpose hasn't been specified, can you specify your own purpose in reading? If not, preview the text in order to prepare text related questions.

2. According to your defined purpose what reading strategies should you apply? Do you need to read the whole text? Do you need to make notes? ... underline certain information? . . . preview? . . scan?

3. Read only for your stated purpose.

\section{REFERENCES}

Bialystok, E. (1978). A theoretical model of second language learning. Language Learning, 28, 69-83.

Bird, Marlene, (1980). Reading Comprehension Strategies: A Direct Teaching Approach. Unpublished Doctoral Thesis, Ontario Institute For Studies in Education, Toronto, Canada.

Blanton, Linda, (1984). Using a hierarchical model to teach academic reading to advanced ESL students. The ESP Journal, 3, 37-46.

Block, Ellen, (1986). The comprehension strategies of second language readers. TESOL Quarterly, 20(3), 463-491. 
Dubin, F., D.E. Eskey, W. Grabe, (1986). Teaching Second Language Reading for Academic Purposes. Reading, Massachusetts: Addison-Wesley.

Geva, Esther, (1983). Facilitating reading comprehension through flowcharting. Reading Research Quarterly, 18, 384-405.

Manzo, Anthony V., Marilyn G. Eanet, (1976). REAP-A Strategy for Improving Reading/Writing/Study Skills. Journal of Reading, 19, 647-652.

Pearson, P. David, Dale D. Johnson, (1978). Teaching Reading Comprehension. New York: Holt, Rinehart, Winston.

Pierce, Mary Eleanor, (1973). Sentence-level expectancy as an aid to advanced reading. TESOL Quarterly, 7(3), 269-277.

Scardamalia, Marlene, Carl Bereiter, Rosanne Steinbach, (1984). Teachability of Reflective Processes in Written Composition. Cognitive Science, 8, 173-190.

Smith, Frank, (1973). Understanding Reading. Toronto: Holt, Rinehart, Winston.

Stanovich, Keith E. (1980). Toward an interactive-compensatory model of individual differences in the development of reading fluency. Reading Research Quarterly, 16(1), 32-71.

Stern, H.H. (1983). Fundamental Concepts of Language Teaching. Toronto: Oxford University Press.

Van Dijk, Teun A., Walter Kintsch, (1983). Strategies of Discourse Comprehension. New York: Academic Press.

\section{THE AUTHOR}

Carol Fraser is an Assistant Professor of ESL at Glendon College, York University where she is currently involved in preparing francophone students to take content courses in English. She previously taught in ESL and teacher training programmes at Concordia, McGill, and the Université de Montréal. 